\title{
Optimal Sales Tax Rebates and Tax Enforcement Consumers
}

\author{
Marcelo Arbex (University of Windsor) \\ Enlinson Mattos (Sao Paulo School of Economics)
}

Working paper $13-02$

Working papers are in draft form. This working paper is distributed for purposes of comment and discussion only. It may not be reproduced without permission of the copyright holder. Copies of working papers are available from the author or at http://ideas.repec.org/s/wis/wpaper.html. 


\title{
Optimal Sales Tax Rebates and
}

\section{Tax Enforcement Consumers}

\author{
Marcelo Arbex* Enlinson Mattos ${ }^{\dagger}$
}

June 12, 2013

\begin{abstract}
We study an optimal commodity taxation problem and show that consumers have an important role as tax enforcers. Firms evade taxes by not issuing sales receipts. Requesting receipts is costly for buyers but forces firms to remit taxes to the government. To compensate buyers, the government offers a tax rebate, which has a non-trivial income effect and modifies the traditional "Ramsey equation". Tax-enforcement policies affect buyers' allocations directly and via the standard changes in the good's price. The optimal policies depend on buyers' auditing and firms' concealment technologies. Welfare is higher if consumer auditing is the only tax enforcement policy.
\end{abstract}

\begin{abstract}
We study an optimal commodity taxation problem and show that consumers have an important role as tax enforcers. Firms evade taxes by not issuing sales receipts. Requesting receipts is costly for buyers but forces firms to remit taxes to the government. To compensate buyers, the government offers a tax rebate, which has a non-trivial income effect and modifies the traditional "Ramsey equation". Tax-enforcement policies affect buyers' allocations directly and via the standard changes in the good's price. The optimal policies depend on buyers' auditing and firms' concealment technologies. Welfare is higher if consumer auditing is the only tax enforcement policy.
\end{abstract}

Keywords: Optimal Taxation, Indirect Tax Evasion, Tax Enforcement and Auditing.

JEL Classification: E62, H21, H26, K42.

*Department of Economics, University of Windsor. Windsor, N9B 3P4, Canada. arbex@uwindsor.ca. †São Paulo School of Economics, Getulio Vargas Foundation. São Paulo, 01332-000, Brazil. enlinson.mattos@fgv.br. Previously entitled "Tax evasion: Is this a government fight, or can anyone join?". We are grateful to Firouz Gahvari, Geoffrey Hewings, Katherine Cuff, Flavio Menezes, Gareth Myles, Mauro Rodrigues, Luca Spataro, Natalie Tiernan, Peter Townley for helpful comments and discussions. We thank Christian Trudeau for constructive comments and valuable suggestions. We also thank seminar participants at the $33^{\circ}$ Meeting of the Brazilian Econometric Society, 2012 Midwest Economic Association Meetings, 13th Public Economic Theory Conference (PET12, Taipei), 2013 Midwest Macroeconomic Meetings, 2013 CEA Meetings and Universidade de São Paulo. All remaining errors are our own. 


\section{Introduction}

In the traditional optimal taxation literature, consumers are often treated as potential tax evaders (Cremer and Gahvari, 1993 and Allingham and Sandmo, 1972). In this paper, we consider an optimal commodity taxation model where buyers have an important role as tax enforcers. We focus on evasion of retail sales taxes. In our economy, the sales tax is remitted only by retail businesses, triggered by sales to final consumers (Slemrod, 2008). However, receipts are not automatically issued as firms attempt to evade sales taxes (Gordon and Li, 2009). To encourage buyers to request receipts (consumer auditing), which is time consuming, the government offers a fraction of the taxes collected by means of a tax rebate. This policy enables buyers to participate in the tax collection process. If a receipt is issued, the transaction leaves a paper trail and the seller is obliged to remit taxes to the tax authority. On sales without receipts, we follow Cremer and Gahvari (1993). Sellers take into account concealment costs and the risk of being audited by the government (government auditing) to decide whether to collect taxes voluntarily on sales without receipts.

The present study contributes to the optimal taxation literature in three ways. First, our optimal tax-enforcement problem is analogous to the standard optimal commodity tax problem (Sandmo, 1974; Atkinson and Stiglitz, 1980; Usher, 1986; Kaplow, 1990) with one relevant difference. In addition to standard changes in the good's price, tax-enforcement policies affect buyers' allocations directly via a non-trivial income effect of the tax rebate. Rebates alleviate consumer's budget constraint producing a direct income effect and an additional response of labor supply. Although the first effect implies a positive effect in terms of welfare, the second effect (i.e., the labor supply response) has an undetermined impact on tax collection. We characterize the policy trade-off faced by the planner when choosing alternative enforcement instruments. The optimal policy choice depends on labor supply responses to tax-enforcement policies which modifies the traditional (dual approach) "Ramsey equation".

Second, we present the Ramsey primal approach solution following Lucas and Stokey (1983) and Chari, Christiano and Kehoe (1991). In particular, we characterize the optimal retail sales tax, the auditing probability and the optimal rebate tax rate. When choosing these policies optimally the planner has to take into account the effect of its policies on the good's price, consumer's income and 
consequently on the economy's welfare. We show that consumer auditing and the firms' concealment technologies play key roles in the determination of optimal policies. We show that if consumers either spend a fixed amount of their time on auditing or do not spend time requesting receipts, the government does not have to reward their behavior and the optimal rebate rate is zero.

Third, we investigate numerically how the unit audit cost, the consumer auditing technology and the concealment cost function affect the optimal policy instruments and how tax rebates to consumers affect compliance and welfare. In an economy with both government and consumer auditing policies, if the unit audit cost is positive, the government has to balance the cost of auditing the economy itself and the cost of having buyers perform this task. As the unit cost of auditing increases, detection probability increases and tax rebate falls. This suggests that when both auditing policies are available, it is optimal to distort the labor-leisure decision the least and bear the cost of wasted resources with direct auditing. When the audit cost is very high, it is optimal for the government not to audit the economy directly. Compliance reaches its minimum, being mainly determined by the firms' concealment technology. The fraction of purchases with receipts is negatively related to the efficacy of the consumer auditing technology.

We consider two extreme cases: the standard case of an economy without consumer auditing and the case when the government does not audit the economy and buyers are solely responsible for tax enforcement. Welfare is higher when the government rewards buyers for their role as tax enforcers. Consumers are better off in this case mainly due to the fact that the labor and tax rebate income allow them to consume more, without giving up too much leisure. Comparing numerical results across the three tax-enforcement regimes we observe that compliance is higher when the government uses both (government and consumer) auditing polices, but welfare is higher if consumer auditing is the only tax enforcement policy.

In practice and in theory, the deterrence approach to curb tax avoidance and evasion is through frequent audits and harsh penalties (Allingham and Sandmo, 1972; Yitzhaki, 1974). Recently, a more enabling approach that views individuals as social actors inclined to comply with the law has received increasing attention (Kagan and Scholz, 1984; Renooy et al., 2004; SBC, 2004; Slemrod, 1992; Williams, 2006; Boadway, Marceau and Mongrain, 2007). The role of the tax authorities is not so much to act as a strict law enforcer that punishes illegal behavior, but more as a service 
provider that secures compliance (Murphy, 2008).

Tax evasion and interactions between consumers and firms have being the focus of a number of studies. To improve tax collection, Tanzi and Shome (1993) suggest a cross tax-control between buyer and seller where the transaction receipt is the main proof of purchase. Das-Gupta and Gang (1996) propose a matching mechanism, essentially a comparison of buyers' and sellers' record of transactions, to improve the enforcement of value added taxes. The possibility of under-reporting prices is examined by Huang and Ueng (2012). Boadway, Marceau and Mongrain (2002) and Chang and Lai (2004) investigate the case where tax evasion requires a collusive behavior between a firm and a consumer. Marchese (2009) studies an economy where money or in-kind subsidies are offered as an incentive for consumers to demand compliance with sales taxes. Search for a seller willing to trade legally is costly for consumers. Differently than our approach, Marchese's model ignores behavioral responses and trade-offs faced by consumers when acting as "tax police".

On the practical level, there has been over the recent years a noticeable increase in the use of measures that encourage compliance by preventing people from engaging in tax evasion and changing attitudes. European Union Member States have targeted consumers with direct tax measures and wage cost subsidies. In the household repair, maintenance and improvement sector, a sector notorious for the prevalence of undeclared work, tax rebates on home maintenance expenses have been available in France under the Universal Service Employment Cheque scheme. Tax reductions for labor costs on home repairs and household services have been introduced in Italy, Luxembourg and Sweden. Businesses registered in the Danish Home Service Scheme provide services to households for which the government reimbursed a proportion of the cost (Williams and Renooy, 2008). Puerto Rico has turned sales receipts into lottery tickets, printing contest numbers on each receipt and holding weekly drawings for cash prizes. The main goal of these programs is to discourage businesses from dodging sales tax by making unrecorded cash sales and to increase compliance of hard-to-tax establishments such as bars, restaurants and small bakeries. Two experiences are related to our approach. In China, the government offers a monetary subsidy to consumers who participate in legal transactions and request sales receipts. The receipts can be used as scratch cards to win

\footnotetext{
${ }^{1}$ Our approach rules out any collaborative behavior or bargain between buyers and sellers to evade taxes. We show in the Appendix A.1 that the planner faces similar policy trade-offs if social norms (Akerlof, 1980; Elster, 1989) dictate a price discount on goods sold without a receipt.
} 
small amounts of cash, but they also serve as lottery tickets for winning larger amounts (Marchese, 2009). The state of São Paulo in Brazil has a program that offers consumers who request sales receipts a rebate of up to thirty percent of the taxes collected in retail purchases. Differently than the Chinese program, consumers enrolled in the program receive their tax rebate periodically on their banking account (Paschoal, 2012).

The paper proceeds as follows. Section 2 presents the model economy. In Section 3 we characterize the optimal tax-enforcement policies and analyze the policy trade-off faced by the government. Section 4 presents a numerical exercise and Section 5 offers concluding comments.

\section{A Model of Retail Sales Tax Evasion}

The model consists of consumers (buyers), firms (sellers) and a government. We assume that there is a continuum of identical sellers and buyers, and that their populations are normalized to unity. Agents in each population engage in many bilateral transactions with those in the other. We assume that each seller engages in a large number of transactions per period, one with every buyer. Transactions involving buyers and sellers can be undertaken either legally or illegally. The nature of a transaction is determined by the remittance of retail sales taxes to the government. If a buyer request a purchase receipt, the seller must remit any taxes triggered by this transaction. Requesting receipts is costly and buyers might not necessarily request them on all of their purchases. This allows sellers to engage in tax evasion (e.g., underreporting, concealment) on the fraction of sales without receipt. A seller can shelter sales from taxation by bearing a resource cost. To encourage buyers to request purchase receipts the government offers a monetary subsidy proportional to the tax revenue collected due to receipt issuance. The government also audits sellers randomly and impose a fine on those caught evading sales tax. Our analysis focuses on representative types of transactions that can occur between sellers and buyers.

\subsection{Firms}

Consider an industry with "many" firms in a competitive market. Production occurs at constant returns to scale and labor $L$ is the only factor of production. The output $Y=L$ is sold to buyers 
at a consumer price of $p$ and sales are subject to a tax $\tau$. Buyers request receipts on a fraction $a$ $\in[0,1]$ of their purchases. We denote this mechanism consumer auditing, where the consumer acts to enforce the tax code. A firm's revenue on sales with receipt is apL. In this case, firms are obliged to remit taxes to the government in the amount of $a \tau p L$. Total (gross) revenue on the amount of sales not subjected to consumer auditing is equal to $(1-a) p L$.

On the amount of sales without receipt, the seller might decide to voluntarily pay taxes to the government or hide it from the tax authorities. Let $\gamma$ be the fraction of sales without receipt for which a seller pays taxes to the government. In this case, a seller collects taxes as if receipts were issued, i.e., $\gamma \tau(1-a) p L$. Sales concealed from the tax authorities entails a resource cost (Cremer and Gahvari, 1993; 1994). The concealment cost $H(\xi)$ is an increasing and convex function of the proportion $\xi=(1-a)(1-\gamma)$ of sales not reported, either because buyers did not ask for a receipt, $(1-a)$, or the seller decides to hide a fraction of its sales, $(1-\gamma)$. The firm incurs these costs regardless whether it issues sales receipts (and collect the appropriate amount of taxes) or is detected by the government evading taxes (and has to pay a penalty). Sellers may be discovered selling without a receipt, i.e., evading retail sales $\operatorname{tax}(\mathrm{RST})$, with probability $\theta \in[0,1]$. If caught evading taxes, a firm must pay $\rho \geq \tau$, which is the standard retail sales tax $\tau$ plus a surcharge factor. If caught evading taxes a seller incurs a cost of $(1-\gamma) \theta \rho(1-a) p L$. We denote this government auditing.

Hence, a seller's problem is to choose $\gamma$ and $L$ to maximize its expected profit $\Pi^{e}$

$$
\Pi^{e}=\{a(1-\tau)+(1-a)[1-\gamma \tau-(1-\gamma) \theta \rho-(1-\gamma) H(\xi)]\} p L-w L
$$

where $w$ is the nominal wage. A seller takes $a$ and government policies $\tau, \theta$, and $\rho$ as given and this profit maximization problem yields the following equilibrium condition:

$$
(w / p)=1-H(\xi)-\theta \rho+(a+(1-a) \gamma)(1-\gamma) H_{\gamma}
$$

where $H_{\gamma}=\partial H(\xi) / \partial \gamma$. According to equation (2), a seller chooses $\gamma$ and $L$ such that the real wage $w / p$ is equal to the expected after-tax revenue on sales with and without receipt. 


\subsection{Households}

Assume all identical buyers are represented by a representative consumer who supplies $L$ units of labor to the market at the wage $w$. A buyer decides whether to request a receipt for a fraction $a$ of his purchases of consumption goods $(c)$ and spends apc on goods with a receipt and $(1-a) p c$ on goods without a receipt.

Requesting receipts (consumer auditing) is time consuming and entails a (time) leisure cost $S$. Time spent on auditing can be associated with a longer time standing in the line waiting for assistance or even to fill out paper work. It can be interpreted in the same spirit as time spent on consumption activities (Gahvari and Yang, 1993; Kleven, 2004; Boadway and Gahvari, 2006; Gahvari, 2007). The auditing time $S(a)$ is concave with respect to fraction of purchases with receipt; $S(0)=0$ and $S(1)=\bar{d}$, where $\bar{d}$ is an upper bound on the leisure cost of auditing activities.

Consumer auditing being costly, buyers need incentives to demand purchase receipts. To reward agents for their role as tax enforcers, the government offers a tax rebate $\phi \in[0,1]$ based on the amount of taxes collected due to consumer auditing. The amount of tax rebate an agent receives depends on the amount of purchases with receipts that triggered tax remittances to the government and is given by $\phi(\tau a p L)$. Hence, the buyer's problem is to

$$
\begin{array}{rl}
\max _{c, L, a} & u(c, 1-L-S(a)) \\
\text { s.t. } p c & =w L+\phi(a \tau p L),
\end{array}
$$

where the time endowment is normalized to 1 , so leisure is $h=1-L-S$, and the instantaneous utility function $u$ is increasing in both arguments and is strictly concave. The consumer takes prices and government policy instruments as given and this optimization problem yields the following equilibrium condition:

$$
(w / p)=\left(u_{2} / u_{1}\right)\left[1-\left(a S_{a} / L\right)\right]
$$

where $S_{a}=d S(a) / d a$. Equation (5) shows that, in equilibrium, the relative price of leisure with respect to consumption when a buyer engages on non-zero consumer auditing is equal to the real wage received. 


\subsection{The Government and Aggregate Resources}

The government finances its expenditures by levying proportional taxes on firms' sales and evasion penalties on sellers as below

$$
G+\theta N=\{a(1-\phi) \tau+(1-a)[\gamma \tau+(1-\gamma) \theta \rho]\} L,
$$

where $G$ is the government spending and $N$ is a fixed unit cost of audit. The right-hand side of equation (6) contains government revenues generated by consumer auditing, seller's voluntary compliance and penalties imposed on those detected evading taxes.

The economy faces an aggregate resource constraint as follows

$$
c+G+\theta N+\xi H(\xi) L=L .
$$

\section{Optimal Taxation and Enforcement}

The objective of the social planner is to choose values of its tax instruments such that the agents utility levels and profits are maximized (i.e., taking into account the equilibrium reaction of private agents to the policy instruments) and the government is constrained to raise a given amount of revenue. There are many competitive equilibria indexed by different government policies and the Ramsey problem is to choose a competitive equilibrium that maximizes welfare. In this section we first study the policy trade-off faced by the government when choosing tax-enforcement instruments. In particular, we follow the Ramsey dual approach and the planner's problem is to choose a retail sales tax, an auditing probability and a tax rebate rate that maximizes the consumer's indirect utility subject to the government budget constraint. Next, we turn to the primal formulation of the optimal taxation problem to characterize the optimal policies.

\subsection{Tax and Enforcement Policies Trade-off}

The structure of this problem is analogous to the standard optimal commodity tax problem with a key difference. In our approach, buyers' allocation can be affected directly not only by the good's 
price $(p)$ but also by the retail sales tax $(\tau)$ and the rebate rate $(\phi)$. The consumer's price $p$ is affected directly by tax enforcement policies and indirectly by responses in allocations $L, a$ and $\gamma$ due to changes in tax-enforcement policies. A buyer's decision to request a receipt is influenced by the tax rebate rate, sales tax and price of the good. A firm's voluntary payment of retail sales taxes is affected by the sales tax, the good's price, the evasion penalty, the concealment cost function and the detection probability.

Using the firm's first-order conditions and normalizing $w=1$, one can write the consumer's price as a function of tax-enforcement policies, $p=F(\tau, \phi, \theta, \rho)$, which in turn comes from $p=$ $\left[1-T^{e}-\xi H(\xi)\right]^{-1}$, where $T^{e}=a \tau(1-\phi)+(1-a)[\gamma \tau+(1-\gamma) \theta \rho]$ is the tax authority's expected sales tax revenue for each unit of output. Note that $\phi$ only affects the good's price indirectly via the proportion of purchases with a sales receipt $a$, while policies $\tau$ and $\theta$ can change prices directly and through $a$ and $\gamma$. Hence, these policies and the good's price are arguments of the buyer's indirect utility which can be written as

$$
v(p, \phi, \tau)=u[c(1 / p, \phi, \tau), L(1 / p, \phi, \tau), S(a(1 / p, \phi, \tau))]
$$

and its corresponding Roy's identity is $\partial v / \partial p=-\mu L / p$, where $\mu$ is the buyer's marginal utility of income. Using the first-order conditions of the consumer's problem, the effects of tax and enforcement policies on the buyer's indirect utility are as follows: $(\partial v / \partial \tau)=(\partial v / \partial p)(\partial p / \partial \tau)-\mu p \phi a L$, $(\partial v / \partial \phi)=(\partial v / \partial p)(\partial p / \partial \phi)-\mu p \tau a L$ and $(\partial v / \partial \theta)=(\partial v / \partial p)(\partial p / \partial \theta)$. See Appendix $A .1$ for details.

The planner's maximization problem in the Lagrangian form is as follows:

$$
£=v(p, \phi, \tau)+\lambda\{-G-\theta N+L[a \tau(1-\phi)+(1-a)(\gamma \tau+(1-\gamma) \theta \rho)]\}
$$

where $\lambda$ is the Lagrangian multiplier on the government's budget constraint and the ordinary demand functions are $x=x(1 / p, \phi, \tau)$ for $x=L, a$ and $\gamma \cdot$

In contrast with the traditional optimal taxation literature, we present the optimal choice of policies $\tau, \theta$ and $\phi$ as a function of labor supply response, rather than consumption's choice. This occurs because the labor supply decision $(L)$ determines the size of production and affects the 
buyer's choice to audit $(a)$. Although the level of production is independent of the firm's decision regarding evasion $(\gamma)$, it is related, via labor supply, to the buyer's auditing time allocation $S(a)$.

When choosing its optimal policies, the planner must take into account their distortionary effects on welfare and their correspondent effects on tax collection. That generates the potential trade-offs associated with a particular policy. In our setup the retail sales tax and the tax rebate distort buyer's allocations and affects the economy's welfare through two channels: the good's price and consumer's income (in utility terms, $\mu p a \phi L$ and $\mu p a \tau L$ ). In contrast, the standard government auditing policy $(\theta)$ only affects welfare through prices.

The effects of tax and enforcement policies on the government's tax collection can be decomposed as follows. For a given policy $\Upsilon=\tau, \theta, \phi$, there is a direct effect of a change on any policy, i.e., $L\left(\partial T^{e} / \partial \Upsilon\right)$, and the effect of that policy $\Upsilon$ on consumer's labor supply, i.e., $T^{e}(\partial L / \partial \Upsilon)$. Traditional auditing only affects an consumer's decision via prices and, therefore, the indirect effect is not present. In Proposition 1 we characterize the trade-offs a planner faces when choosing the optimal policies.

Proposition 1 The trade-offs between (i) the auditing probability and the tax rebate rate and (ii) the retail sales tax and the tax rebate rate are represented by the following expressions:

$$
\begin{aligned}
& \frac{\frac{\partial p}{\partial \phi}}{\frac{\partial p}{\partial \theta}}=\frac{\left[T^{e} \frac{\partial L}{\partial \phi}+L \frac{\partial T^{e}}{\partial \phi}\right]+(\mu / \lambda) p a \tau L}{\left[-N+L \frac{\partial T^{e}}{\partial \theta}\right]} \\
& \frac{\partial p}{\partial \phi}=\frac{\left[T^{e} \frac{\partial L}{\partial \phi}+L \frac{\partial T^{e}}{\partial \phi}\right]+(\mu / \lambda) p a \tau L}{\left[T^{e} \frac{\partial L}{\partial \tau}+L \frac{\partial T^{e}}{\partial \tau}\right]+(\mu / \lambda) p \phi a L}
\end{aligned}
$$

\section{Proof. See Appendix A.2.}

According to Proposition 1, at the optimum, any given pair of policy instruments must be chosen such that the rates of substitution between two policies that keep welfare and tax collection (at the margin) constant are equalized. For instance, the left-hand side of equation (10) denotes the rate of substitution between $\phi$ and $\theta$ such that the impact on welfare via price $(p)$ is constant. The right-hand side of equation (10) is the rate of substitution between these policies such that tax collection is constant; and an additional component. The terms $(\mu / \lambda) p a \tau L$ and $(\mu / \lambda) p \phi a L$ capture the effect of policy $\phi$ and $\tau$ on welfare via income. Therefore, incorporating a tax rebate 
into the policy scheme to combat evasion adds a tax collection effect, $\left[T^{e}(\partial L / \partial \phi)+L\left(\partial T^{e} / \partial \phi\right)\right]$, and a welfare effect.

The policy trade-off can also be viewed as follows. Any vector of prices and allocations can be achieved by various combinations of auditing probabilities, tax and tax rebate rates. However, at the optimum, these policies $(\tau, \theta$ and $\phi)$ must be such that the government's net tax revenues are maximal, conditional on prices and on the marginal income (in utility terms). Otherwise, it would be possible to increase tax revenue while keeping welfare constant, which contradicts the optimality condition. Hence, a necessary condition for the net tax revenue to be maximized is that the rates of substitution are equalized across policy instruments as stated in equations (10) and 11). In our model these policies affect welfare not only via the good's price but also via the consumer's income.

Propostion 2 show the "Ramsey equation" for our economy and how the optimal taxation rule is modified due to the buyers' role as tax enforcers. This version of the "Ramsey equation" takes into account the fact that tax and enforcement policies distort the labor supply rather than the consumption choice. The fact that buyers can act as tax enforcers has essentially two effects, i.e., taxation has an income effect, via rebates, and the buyers' net income is directly related to tax changes and tax-enforcement policies affect buyers' allocations $(L, a)$ directly, in addition to (standard) changes in the good's price.

Proposition 2 The optimal tax policies satisfy the following relationship:

$$
\frac{T^{e}}{p}=\left[\left(\frac{\mu}{\lambda}\right)\left(\frac{1}{p}+\frac{p \phi a}{\frac{\partial p}{\partial \tau}}\right)-\left(\frac{\frac{\partial T^{e}}{\partial \tau}+\epsilon^{(L, \tau)}}{\frac{\partial p}{\partial \tau}}\right)\right]\left(\frac{1}{\epsilon^{(L, p)}}\right)
$$

Proof. See Appendix A.2.

If evasion is not possible $\left(T^{e}=\tau, \partial p / \partial T^{e}=1\right)$, no rebate is offered $(\phi=0)$ and taxes would affect labor supply only via prices, rending the direct effect of taxes on labor supply null $\left(\epsilon^{(L, \tau)}=\right.$ 0). Equation (12) would then be the traditional Ramsey expression where taxes are inversely proportional to the price elasticity. ${ }^{2}$ According to equation (12), the more prices are tax-distorted (large $\partial p / \partial \tau)$, the closer the optimum tax should be to the case without evasion and tax rebates.

\footnotetext{
${ }^{2} \mathrm{~A}$ corresponding "Ramsey equation" considering labor distortion along supply curve instead of consumption counterpart for the demand curve would be $[\tau p(\partial L / \partial p)] / L=(\mu / \lambda) / p$.
} 
In this case, the policy $\tau$ achieves its optimal through price changes and no additional distortion is necessary.

The interpretation of equation (12) depends on the sign of the tax-response of the good's price to changes in the retail sales tax. If $\partial p / \partial \tau$ is positive (negative) the interpretation is as follows. First, the larger the buyer's rebate income $(a \phi p)$ - in terms of welfare when multiplied by $\mu / \lambda$ the higher (lower) the expected tax revenue should be. As the government wants to maximize the buyer's welfare, a marginal increase in the tax rate produces a large effect on the buyer's income that leads to a larger (lower) optimal expected real tax revenue $\left(T^{e} / p\right)$. Second, the larger the distortion on the buyer's response to changes in the retail sales tax, i.e., the large $\partial T^{e} / \partial \tau$ and $\epsilon^{(L, \tau)}$, the lower (larger) taxes should be in order to minimize such distortion.

\subsection{Characterization of optimal tax and audit policies}

We now turn to the characterization of the optimal policies as a function of allocations. Taking into account the private agents' equilibrium reactions to the tax and enforcement system, the planner's problem is to choose $\{\tau, \theta, \phi\}$, which maximizes social welfare and satisfies the economy's resource constraint and an implementability constraint, a second-best optimal tax problem (Chari, Christiano and Kehoe, 1994).

The implementability constraint is similar to the objective function, equation (3), and given the Lagrange multiplier $\lambda_{1}$ (which is endogenous), it is possible to write the pseudo-welfare function of the social planner as

$$
Z\left(c, L, a ; \lambda_{1}\right) \equiv u(c, 1-L-S(a))+\lambda_{1}\left[u_{1} c-u_{2} L\right]
$$

where $\lambda_{1}$ is the Lagrange multiplier on the implementability constraint. The planner's problem is hence to maximize (13) subject to economy's resource constraint, and $\bar{G}, N$, $\rho$ are given (see Appendix A.3 for derivation details). Solving the Ramsey planner's maximization problem we find the optimal allocations $c^{*}, L^{*}, a^{*}$ and $\gamma^{*}$. The following proposition shows that policy instruments are affected by the unit audit cost, the consumer auditing technology and the concealment cost function. 
Proposition 3 Suppose that the evasion penalty $\rho$ is fixed. If the government has access to a retail sales tax $\tau$, an auditing probability $\theta$ and a tax rebate $\phi$, then, the optimal policies are as follows:

$$
\begin{aligned}
\tau^{*} & =\left[\Phi_{L}-\Phi_{c}^{*} \frac{Z_{L}^{*}}{Z_{c}^{*}}+\Phi_{\gamma}^{*}\left(\frac{1-a^{*}-\left(1-a^{*}\right) \gamma^{*}}{\left(1-a^{*}\right) L^{*}}\right)\right] N-M^{*}, \\
\theta^{*} & =\frac{1}{\rho}\left\{\left[\Phi_{L}^{*}-\Phi_{c}^{*} \frac{Z_{L}^{*}}{Z_{c}^{*}}-\Phi_{\gamma}^{*}\left(\frac{a^{*}+\left(1-a^{*}\right) \gamma^{*}}{\left(1-a^{*}\right) L^{*}}\right)\right] N-M^{*}\right\}, \\
\phi^{*} & =\frac{Z_{c}^{*}\left\{\left[\left(1-\gamma^{*}\right) H\left(\xi^{*}\right)-\xi^{*} H_{a^{*}}\right] L^{*}-\Phi_{a}^{*} N\right\}}{\beta u_{1}^{*} L^{*}\left(1+\Phi_{c}^{*} N\right)\left\{\left[\Phi_{L}^{*}-\Phi_{c}^{*} \frac{Z_{L}^{*}}{Z_{c}^{*}}+\Phi_{\gamma}^{*}\left(\frac{1-a^{*}-\left(1-a^{*}\right) \gamma^{*}}{\left(1-a^{*}\right) L^{*}}\right)\right] N-M^{*}\right\}},
\end{aligned}
$$

where $M^{*}=\left(Z_{L}^{*} / Z_{c}^{*}\right)+\left(u_{2}^{*} / u_{1}^{*}\right)\left(1-\left(a^{*} S_{a}^{*} / L^{*}\right)\right)$.

Proof. See Appendix A.3.

Notice that if the unit cost of audit $N$ is zero, from expressions (14) and (15), the government will set the retail sales tax and the audit probability such that the following condition is satisfied: $\tau^{*}=\theta^{*} \rho$. This means that the expected penalty for tax evasion is equal to the retail sales tax. Moreover, the optimal tax rebate rate is negatively related to the auditing probability as these two auditing policies are alternative tools that the government has to fight tax evasion. This result is also verified for any audit (positive) cost $N$ when the firm's concealment cost is zero, i.e., $H\left(\xi^{*}\right)=0$. Intuitively, the planner will set the optimal retail sales tax and the optimal expected penalty to the same level such that firms are indifferent between collecting taxes voluntarily or evading them and being caught by the government.

An interesting result emerges regarding the consumer auditing technology. If buyers spend a fixed amount of their time on auditing, i.e., $S(a)=\bar{d}$ and $S_{a}^{*}=0$, the planner does not have to reward buyers and the optimal rebate rate is zero $\left(\phi^{*}=0\right)$. A zero tax rebate rate is also optimal when, on the other hand, a buyer do not spend time requesting receipts (for instance, due to technological progress on the tax remittance process). This can be illustrated by assuming $\bar{d}=0$. In this case, $Z_{a}^{*}=0$ and following the proof of Proposition 3, it is optimal to set $\phi^{*}=0$. 


\section{Numerical Results}

\subsection{Functional Forms and Parameterization}

In this section we present the results of a numerical analysis of our model to obtain further insights into the relationship between alternative auditing instruments and the retail sales tax as well as a quantitative sense of our theoretical results. We investigate numerically how the unit audit cost, the consumer auditing technology and the concealment cost function affect the optimal policy instruments. We also assess how tax rebates to consumers affect compliance and welfare.

For the purpose of this exercise, we use the following functional forms:

$$
\begin{aligned}
\text { Preferences: } & u(c, h)=\frac{c^{1-\sigma}}{1-\sigma}+\beta \frac{(1-L-S(a))^{1+\frac{1}{\eta}}}{1+\frac{1}{\eta}}, \\
\text { Technology: } & F(L)=L, \\
\text { Auditing Technology: } & S(a)=\bar{d} a^{\delta}, \\
\text { Concealment Cost: } & H(\xi)=\xi^{\varkappa}=[(1-a)(1-\gamma)]^{\varkappa},
\end{aligned}
$$

where $\beta$ is the weight on leisure and $\delta$ and $\varkappa$ are the curvature parameters of the auditing technology and concealment cost functions, respectively. The parameter $\delta$ measures the efficacy of the consumer auditing technology. When $\delta$ is close to 0 , the consumer is able to audit more, i.e., ask for receipts on a larger fraction of his purchases, with relatively little (leisure) cost. When $\delta$ is close to 1 , request receipts is more difficult, and requires a greater investment of time. This function can also be related to the information transmission technology used by sellers. Modern technologies such as better internet connection, computerized fiscal receipts emission make auditing less (time) costly for buyers.

The baseline value for $\sigma$ is 1 , which implies a relative risk aversion of 1 . The baseline value for $\eta$ is 0.4 (Blundell and MaCurdy, 1999). There are no available estimates in the literature regarding the parameters governing the consumer auditing and concealment technologies. We assume that, in equilibrium, people spend about one-quarter of their available time working and three percent of their time auditing. The weight on leisure, $\beta$, is hence set to match initial non-leisure activities of $L+S(a)=0.28$. These parameters $(\sigma, \eta, \beta)$ are kept constant throughout the experiments below. 
Government purchases, $G$, are such that the ratio of government purchases to GDP generated by the model with initial policy is 20 percent of GDP. We assume the evasion penalty to be fixed at one hundred percent of the tax evaded. Both $G$ and $\rho$ are not changing in the exercise that follows. Our benchmark values for the cost of auditing, parameters of the auditing technology and concealment cost functions are: $N=0.00, \bar{d}=0.03, \delta=0.30$ and $\varkappa=5.00$. We then conduct sensitivity analysis.

This numerical exercise is divided in three steps. First, we analyze the economy as described in Section 2 and we consider the implications of both government and consumer auditing policies. We characterize numerically the optimal policies and we report compliance measures $(a$ and $\gamma)$ and optimal allocations $(c, L$ and $S)$. Next we consider two alternative tax-enforcement policy regimes: (i) an economy without consumer auditing, where the only instrument available to the government to enforce the tax code is the standard (government) auditing probability and (ii) the case when the government transfers completely to buyers the role of auditing the economy, i.e., the detection probability by the government is constrained to be zero. ${ }^{3}$

\subsection{Government and Consumer Auditing Policies}

When the government has two auditing policies at its disposal, i.e., $\theta$ and $\phi$, it has to balance the impact of both on the good's price and the buyer's income, which consequently has an impact on the economy's welfare. The results for this tax regime are presented in Table 1. Notice that when there is no cost for the government to engage in direct auditing, i.e., $N=0$, it is optimal for the government to audit the economy itself and have consumers do so too. By offering a tax rebate the government encourages individuals to ask for receipts which alleviates the need to audit the economy via $\theta$ at a higher rate. If the planner were to set the rebate rate equals to zero and increase the detection probability to increase compliance, it would increase the good's price and that would make buyers worse off. This policy also allows for a decrease in the sales tax.

\footnotetext{
${ }^{3}$ The Ramsey problems for the government auditing only and the individual auditing only regimes are available upon request.
} 
Table 1 - Optimal Policies and Allocations

Government and Consumer Auditing

\begin{tabular}{rlcccc}
\hline & $N=0.00$ & $N=0.001$ & $N=0.003$ & $N=0.005$ \\
\cline { 2 - 5 } Policies: & Retail Sales Tax $\tau^{*}$ & 0.2801 & 0.2867 & 0.3007 & 0.3160 \\
& Detection Probability $\theta^{*}$ & 0.2859 & 0.2864 & 0.2999 & 0.3146 \\
& Tax Rebate $\phi^{*}$ & 0.0775 & 0.0752 & 0.0707 & 0.0661 \\
Compliance: & Purchases with receipt $a^{*}$ & 0.6444 & 0.6422 & 0.6374 & 0.6321 \\
& Sales Reported $\gamma^{*}$ & 0.6005 & 0.6003 & 0.5997 & 0.5990 \\
Allocations: & Consumption $c^{*}$ & 0.3306 & 0.3279 & 0.3221 & 0.3158 \\
& Leisure $h^{*}$ & 0.5431 & 0.5430 & 0.5427 & 0.5424 \\
& Auditing time $S\left(a^{*}\right)$ & 0.0263 & 0.0263 & 0.0262 & 0.0261 \\
\cline { 2 - 5 } & Welfare $U^{*}$ & -0.7628 & -0.7713 & -0.7897 & -0.8103 \\
\hline
\end{tabular}

Facing a higher cost of auditing the economy directly, for instance $N=0.001$, the government balances the cost of auditing the economy itself and the cost of having buyers perform this task. Interestingly, as the unit cost of auditing increases, detection probability increases and tax rebate falls. This result suggests that, in our framework, when both auditing policies are available, it is optimal to distort the labor-leisure decision the least and bear the cost of wasted resources with direct auditing. As $N$ increases, total compliance falls and retail sales tax increases accordingly. When the audit cost is very high, for instance, $N=0.05$, it is optimal for the government not to audit the economy directly (i.e., $\theta^{*}=0$ ). Compliance reaches its minimum, being mainly determined by the firms' concealment technology.

Tables 2 and 3 show how the optimal policies and compliance measures are affected by a variety of parameter changes. We restrict our attention to the parameters pertinent to the auditing technology and the concealment cost function. We fix the unitary cost of auditing at $N=0.005$. Table 2 shows that the retail sales tax, detection probability and sales voluntarily reported by firms are quite insensitive to changes in the auditing technology concavity parameter $\delta$. On the other hand, as expected, the fraction of purchases with receipts $a^{*}$ is negatively related to $\delta$, while the tax rebate decreases as $\delta$ decreases. The intuition for this is as follows. For instance, when $\delta$ decreases from 
0.30 to 0.20 , it becomes (at the margin) less costly for buyers to request receipts and $a^{*}$ increases. Because consumers can request more receipts at a lower (leisure) cost, the government can offer a lower tax rebate in return and hence $\phi^{*}$ is smaller.

It is interesting to consider two extreme cases, namely when there is a sunk cost of auditing and when it is costless to ask for receipts. If the cost of auditing is positive and fixed, i.e., when $\delta=0.00$, consumers will necessarily spend three percent of their time auditing $(\bar{d}=0.03)$, they ask for receipts on all purchases, and the tax rebate is zero reflecting the fact the government doesn't need to reward consumers for a task they will perform anyway. Full compliance through purchases with receipts can also be obtained if no time is spent on auditing $(\bar{d}=0.00)$. Similarly no tax rebate is offered, but the retails sales tax is lower. This is possible because the consumer can, keeping its optimal level of leisure constant, work more. It hence increases production, sales and consumption, and welfare is higher in this case.

Table 2 - Optimal Policies and Compliance

Government and Consumer Auditing $\left(N=0.005^{\star}, \varkappa=5.00^{\star}\right)$

\begin{tabular}{|c|c|c|c|c|c|}
\hline & \multirow{2}{*}{$\begin{array}{l}\bar{d}=0.03^{\star} \\
\delta=0.30^{\star}\end{array}$} & \multicolumn{2}{|c|}{$\bar{d}=0.03^{\star}$} & \multicolumn{2}{|c|}{$\delta=0.30^{\star}$} \\
\hline & & $\delta=0.00$ & $\delta=0.20$ & $\bar{d}=0.00$ & $\bar{d}=0.02$ \\
\hline Retail Sales Tax $\tau^{*}$ & 0.3160 & 0.2659 & 0.3160 & 0.2659 & 0.3021 \\
\hline Detection Probability $\theta^{*}$ & 0.3146 & n.r. & 0.3153 & n.r. & 0.3013 \\
\hline Tax Rebate $\phi^{*}$ & 0.0661 & 0.0000 & 0.0428 & 0.0000 & 0.0425 \\
\hline Purchases $\mathrm{w} /$ receipt $a^{*}$ & 0.6321 & 1.0000 & 0.6933 & 1.0000 & 0.6843 \\
\hline Sales Reported $\gamma^{*}$ & 0.5990 & n.r. & 0.5991 & n.r. & 0.5991 \\
\hline
\end{tabular}

* : baseline values; n.r.: not reported.

Table 3 shows that optimal policies and compliance are responsive to changes in the concealment technology parameter $\varkappa$. For a convex concealment cost function, as $\varkappa$ decreases from 5.00 to 1.50 it becomes more costly to hide and not report sales. Firms react by increasing the amount of sales they voluntarily report (from $59 \%$ to $62 \%$ ) and the detection probability falls accordingly. In this case, total compliance $a^{*}+\left(1-a^{*}\right) \gamma^{*}$ increases (from 0.8524 to 0.8697 ). The equilibrium good's price is lower when $\varkappa=1.50$ and consumption and purchase with receipts increase. Even though 
the tax rebate rate $\phi^{*}$ falls, the amount a buyer receives from the government, i.e., $\phi^{*} p^{*} a^{*} \tau^{*} L^{*}$, stays roughly the same as the retail sales tax rate increases. Results presented in Tables 2 and 3 illustrate the fact that optimal policies, compliance and allocations are quite sensitive to different combinations of consumer auditing technology and concealment costs.

\begin{tabular}{|c|c|c|c|}
\hline \multicolumn{4}{|c|}{ Government and Consumer Auditing $\left(N=0.005^{\star}\right)$} \\
\hline & \multicolumn{3}{|c|}{$\bar{d}=0.03^{\star}, \delta=0.30^{\star}$} \\
\hline & $\varkappa=1.50$ & $\varkappa=5.00^{\star}$ & $\varkappa=8.50$ \\
\hline Retail Sales Tax $\tau^{*}$ & 0.3375 & 0.3160 & 0.3150 \\
\hline Detection Probability $\theta^{*}$ & 0.2011 & 0.3146 & 0.3150 \\
\hline Tax Rebate $\phi^{*}$ & 0.0608 & 0.0661 & 0.0662 \\
\hline Purchases with receipt $a^{*}$ & 0.6562 & 0.6321 & 0.6332 \\
\hline Sales Reported $\gamma^{*}$ & 0.6211 & 0.5990 & 0.6000 \\
\hline
\end{tabular}

* : baseline values.

\subsection{Alternative Tax-Enforcement Regimes: Compliance versus Welfare}

Table 4 presents the results for our benchmark parameterization for an economy without consumer auditing - an economy where the only instrument available to the government to enforce the tax code is the standard (government) auditing probability. When there are no costs to audit the economy, i.e., $N=0$, the planner sets the retail sales tax equal to the expected penalty, and guarantees full compliance of firms with the tax code. As expected, when the cost of auditing increases, the detection probability decreases and firms react to it by reducing the amount of sales voluntarily reported. A lower level of compliance is associated with a smaller tax base and, in order to finance an exogenously given government spending, the retail sales tax must increase. Welfare losses are greater the higher the unitary cost of auditing as well as the higher taxes are, which increases deadweight losses.

Next, we allow consumer auditing to be the only mechanism through which firms can be audited. In other words, the auditing probability $\theta$ is constrained to be zero. If there is no chance of being caught evading taxes, firms would not spend resources to hide sales the government and, moreover, 
firms have no incentive to remit taxes voluntarily to the tax authority. In this case, compliance is solely determined by the behavior of the buyers. Table 5 presents the results for this tax-enforcement regime.

\begin{tabular}{|c|c|c|c|}
\hline & $N=0.00$ & $N=0.001$ & $N=0.005^{\star}$ \\
\hline Retail Sales Tax $\tau^{*}$ & 0.3116 & 0.3216 & 0.4013 \\
\hline Detection Probability $\theta^{*}$ & 0.9736 & 0.3213 & 0.3047 \\
\hline Sales Reported $\gamma^{*}$ & 1.0000 & 0.8652 & 0.5622 \\
\hline Consumption $c^{*}$ & 0.2210 & 0.2178 & 0.2035 \\
\hline Leisure $h^{*}$ & 0.6790 & 0.6790 & 0.6790 \\
\hline Welfare $U^{*}$ & -0.9053 & -0.9199 & -0.9878 \\
\hline
\end{tabular}

^ : baseline values.

As the consumer auditing technology parameter $\delta$ decreases from 0.30 to 0.20 , total compliance $a^{*}$ increases from 0.6439 to 0.7023 , allowing the government to reduce the retail sales tax $\tau^{*}$ and the optimal tax rebate rate $\phi^{*}$. Full compliance is reached and no rebate is offered if either $\delta=0.00$ or $\bar{d}=0.00$. Retail sales taxes are lower when $\bar{d}=0.00$ because time not used for auditing is shifted to labor, which increases production, sales and, consequently, the tax base. The optimal sales tax rate is the lowest in this case.

Finally, we compare numerical results of (baseline) compliance and welfare levels across three tax enforcement policy regimes, namely (i) government and consumer auditing (Table 1), (ii) government auditing only (Table 4) and (iii) consumer auditing only (Table 5). We observe that welfare is higher when the government rewards buyers for their role as tax enforcers. Consumers are better off in this case mainly due to the fact that the labor and tax rebate income allow them to consume more, without giving up too much leisure. 
Table 5 - Optimal Policies and Compliance

Consumer Auditing Only

\begin{tabular}{|c|c|c|c|c|c|}
\hline & \multirow{2}{*}{$\begin{aligned} \bar{d} & =0.03^{\star} \\
\delta & =0.30^{\star}\end{aligned}$} & \multicolumn{2}{|c|}{$\bar{d}=0.03^{\star}$} & \multicolumn{2}{|c|}{$\delta=0.30^{\star}$} \\
\hline & & $\delta=0.00$ & $\delta=0.20$ & $\bar{d}=0.00$ & $\bar{d}=0.02$ \\
\hline Retail Sales Tax $\tau^{*}$ & 0.4355 & 0.2301 & 0.3992 & 0.2046 & 0.3882 \\
\hline Tax Rebate $\phi^{*}$ & 0.1718 & 0.0000 & 0.1688 & 0.0000 & 0.1718 \\
\hline Purchases $\mathrm{w} /$ receipt $a^{*}$ & 0.6439 & 1.0000 & 0.7023 & 1.0000 & 0.6939 \\
\hline Consumption $c^{*}$ & 0.3306 & 0.3346 & 0.3291 & 0.3886 & 0.3483 \\
\hline Leisure $h^{*}$ & 0.5431 & 0.5354 & 0.5429 & 0.5114 & 0.5338 \\
\hline Welfare $U^{*}$ & -0.7628 & -0.7676 & -0.7677 & -0.6665 & -0.7309 \\
\hline
\end{tabular}

* : baseline values.

When the government audits the economy directly (Table 4), compliance is only due to firms' voluntarily payment of retail sales taxes on 56 percent of the their sales. If the government introduces the tax rebate policy to encourage consumers to act as tax enforcers (Table 1), optimum compliance increases to 85 percent, which breaks down as follows. Consumers request receipts on 63 percent of their purchases and firms voluntarily pay taxes on 60 percent of sales without receipt, i.e., $a^{*}+\left(1-a^{*}\right) \gamma^{*}=0.6321+(1-0.6321) \cdot 0.5990=0.8524$. If consumer auditing is the only enforcement policy (Table 5), optimum compliance falls to 64 percent but it is still higher than under the government auditing regime only. The comparison of these three regimes suggests that compliance is higher when both government and consumer auditing polices are in place, but welfare is higher if consumer auditing is the only tax enforcement policy.

\section{Conclusion}

This paper investigates optimal tax and audit policies where both consumers and tax administrators can engage in auditing. In particular, our model allows consumers to play a role in auditing businesses to enforce compliance with the tax code and tax remittances to the government. To reward buyers for their auditing effort, the government returns a portion of the tax collected to them. Tax rebates have a non-trivial income effect when buyers act as tax enforcers. Rebates alleviate 
consumer's budget constraint which in turn produces a direct income effect and an additional response of labor supply. We characterize the optimal retail sales tax, the auditing probability and the optimal rebate tax rate and show that the individuals' auditing and the firms' concealment technologies and the unitary audit cost play key roles in the determination of optimal policies. We also analyze the policy trade-off faced by the government. Numerically, our results suggest that compliance is higher when both auditing policies are in place, but welfare is higher if consumer auditing is the only tax enforcement policy.

\section{Appendix}

\section{A.1. Price Discount and Social Norms on Sales without Receipts}

The tax rebate policy encourages buyers to request receipts (consumer auditing). In our baseline model (Section 2) buyers must decide whether ask for receipts based only on the leisure cost of doing so. However one can think of other reasons buyers might not ask for receipts. For instance, buyers and sellers could engage in a collaborative and strategic behavior to evade taxes or they could bargain over the price without receipt. Our approach rules out these alternatives. In this Appendix we study the case where the price wedge between goods sold with and without a receipt is determined by social norms. That is, we assume that social norms (Akerlof, 1980; Elster, 1989) dictate a price discount on goods sold without a receipt and we show that, in this case, the planner faces similar policy trade-offs as those presented in Section 3.1. In what follows we implicit assume that buyers and sellers respect existing social norms and design and honor informal trade contracts (Young and Burke, 2001).

For transactions with receipts, let the consumer price be $p_{r}^{c}=p$. It is understood by sellers and buyers that sales without receipts occur at a lower price $\left(p_{n r}^{c}\right)$. We define the consumer price on purchases without receipt as follows: $p_{n r}^{c}=(1-k) p$. Hence, the difference between sales prices with and without receipts, i.e., $p$ and $p_{n r}^{c}$, respectively, is determined by social norms. The price discount on sales without receipt $k \in[0, \bar{k}]$ is treated here as exogenously determined by social norms, where $\bar{k}<1$ is an upper bound on $k$ to rule out $p_{n r}^{c}=0$.

Following the same steps of Section 2, a seller's problem is to choose $\gamma, L$ to maximize expected profit $\Pi^{e}$

$$
\Pi^{e}=\{a(1-\tau)+(1-a)(1-k)[1-\gamma \tau-(1-\gamma) \theta \rho-(1-\gamma) H(\xi)]\} p L-w L .
$$

and the buyer's problem is as follows

$$
\max _{c, L, d} u(c, 1-L-S(a)) \quad \text { s.t. } \quad a p c+(1-a)(1-k) p c=w L+\phi(a \tau p L)
$$

To easy notation, the buyer's budget constraint can be written as $c=(\widetilde{w} L) / p$, where $\widetilde{w}=$ $(w+\phi \tau p a) /(a+(1-a) k)$. Hence, a buyer's indirect utility function can be written as $v(p, \phi, \tau ; k)=$ $u[c(1 / p, \phi, \tau ; k), L(1 / p, \phi, \tau ; k), S(a(1 / p, \phi, \tau ; k))]$. The derivative of the indirect utility function $v(p, \phi, \tau ; k)$ 
with respect to its arguments is as follows:

$$
\frac{\partial v}{\partial p}=\mu\left[L a \tau \phi+\left(\frac{\partial a}{\partial p}\right)(1-k)(p c-\widetilde{w} L)\right]
$$

Notice that the second term of this equation is equal to zero, since the buyer's budget constraint implies that $p c-\widetilde{w} L=0$. Hence, $\partial v / \partial p=\mu[L a \tau \phi]$. Similarly, $\partial v / \partial \tau=\mu[L a p \phi]$ and $\partial v / \partial \phi=$ $\mu[\operatorname{Lap} \tau]$.

The planner's maximization problem can thus be written in the Lagrangian form as follows:

$$
£=v(p, \phi, \tau ; k)+\lambda\{-G-\theta N+L[a(1-\phi) \tau+(1-a) k(\gamma \tau+(1-\gamma) \theta \rho)]\},
$$

where $\lambda$ is the Lagrangian multiplier on the government's budget constraint. The first-order conditions of this problem with respect to $\tau, \phi$ and $\theta$ are, respectively:

$$
\begin{aligned}
\frac{\partial v}{\partial \tau}+\frac{\partial v}{\partial p} \frac{p}{\partial \tau}+\lambda\left[\frac{\partial R}{\partial \tau}\right] & =0 \\
\frac{\partial v}{\partial \phi}+\frac{\partial v}{\partial p} \frac{p}{\partial \theta}+\lambda\left[\frac{\partial R}{\partial \phi}\right] & =0 \\
\frac{\partial v}{\partial p} \frac{p}{\partial \theta}+\lambda\left[\frac{\partial R}{\partial \theta}\right] & =0
\end{aligned}
$$

where

$$
\begin{aligned}
& \frac{\partial R}{\partial \tau}=\left[\begin{array}{l}
a(1-\phi)+\left(\frac{\partial a}{\partial \tau}+\frac{\partial a}{\partial p} \frac{\partial p}{\partial \tau}\right)(\tau(1-\phi)-k(\gamma \tau+(1-\gamma) \theta \rho)) \\
\left.+(1-a) k\left(\gamma+\left(\frac{\partial \gamma}{\partial p}+\frac{\partial \gamma}{\partial a} \frac{\partial a}{\partial p}\right) \frac{\partial p}{\partial \tau}+\frac{\partial \gamma}{\partial \tau}+\frac{\partial \gamma}{\partial a} \frac{\partial a}{\partial \tau}\right)(\tau-\theta \rho)+\rho(1-\gamma)\right)
\end{array}\right] L \\
& +\left(\frac{\partial L}{\partial p} \frac{\partial p}{\partial \tau}+\frac{\partial L}{\partial \tau}\right)[a \tau(1-\phi)+(1-a) k(\gamma \tau+(1-\gamma) \theta \rho)] \\
& \frac{\partial R}{\partial \phi}=\left[\begin{array}{l}
-a \tau+\left(\frac{\partial a}{\partial \phi}+\frac{\partial a}{\partial p} \frac{\partial p}{\partial \phi}\right)(\tau(1-\phi)-k(\gamma \tau+(1-\gamma) \theta \rho)) \\
+(1-a) k\left(\left(\frac{\partial \gamma}{\partial p}+\frac{\partial \gamma}{\partial a} \frac{\partial a}{\partial p}\right) \frac{\partial p}{\partial \phi}+\frac{\partial \gamma}{\partial \phi}+\frac{\partial \gamma}{\partial a} \frac{\partial a}{\partial \phi}\right)(\tau-\theta \rho)+\rho(1-\gamma)
\end{array}\right] L \\
& +\left(\frac{\partial L}{\partial p} \frac{\partial p}{\partial \phi}+\frac{\partial L}{\partial \phi}\right)[a \tau(1-\phi)+(1-a) k(\gamma \tau+(1-\gamma) \theta \rho)] \\
& \frac{\partial R}{\partial \theta}=\left[\begin{array}{l}
\left(\frac{\partial a}{\partial p} \frac{\partial p}{\partial \theta}\right)(\tau(1-\phi)-k(\gamma \tau+(1-\gamma) \theta \rho)) \\
+(1-a) k\left(\left(\frac{\partial \gamma}{\partial \theta}+\left(\frac{\partial \gamma}{\partial p}+\frac{\partial \gamma}{\partial a} \frac{\partial a}{\partial p}\right) \frac{\partial p}{\partial \theta}\right)(\tau-\theta \rho)+\rho(1-\gamma)\right)
\end{array}\right] L \\
& +\left(\frac{\partial L}{\partial p} \frac{\partial p}{\partial \theta}\right)[a \tau(1-\phi)+(1-a) k(\gamma \tau+(1-\gamma) \theta \rho)]-N
\end{aligned}
$$

Manipulating equations $(21)-(23)$, the following propositions shows that is possible to obtain similar policy trade-offs as those presented in Proposition 1.

Proposition 4 Trade-offs between (i) the auditing probability and the tax rebate rate and (ii) the 
retail sales tax and the tax rebate rate are represented by the following relationships:

$$
\begin{aligned}
& \frac{\frac{\partial p}{\partial \phi}}{\frac{\partial p}{\partial \theta}}=\frac{\left[T^{e} \frac{\partial L}{\partial \phi}+L \frac{\partial T^{e}}{\partial \phi}\right]+(\mu / \lambda) p a \tau L}{\left[-N+L \frac{\partial T^{e}}{\partial \theta}\right]} \\
& \frac{\frac{\partial p}{\partial \phi}}{\frac{\partial p}{\partial \tau}}=\frac{\left[T^{e} \frac{\partial L}{\partial \phi}+L \frac{\partial T^{e}}{\partial \phi}\right]+(\mu / \lambda) p a \tau L}{\left[T^{e} \frac{\partial L}{\partial \tau}+L \frac{\partial T^{e}}{\partial \tau}\right]+(\mu / \lambda) p \phi a L}
\end{aligned}
$$

where $T^{e}=[a(1-\phi) \tau+(1-a) k(\gamma \tau+(1-\gamma) \theta \rho)]$.

Finally, it is possible to imagine a situation where social norms dictate a large enough price discount such that buyers would be discourage to ask for purchase receipts. However, in the presence of a tax rebate policy and social norms it is possible to show that there is a threshold price discount $\tilde{k}$ such that any buyers would still request receipts on a non-negative fraction of their purchases, i.e., $a>0$. For price discounts above $\tilde{k}, a=0$.

To show this result consider the buyer's problem (18) and the marginal rate of substitution between $a$ and $L$ :

$$
S_{a}=\frac{(\phi \tau L)-k p c}{w+\phi \tau a p}
$$

Interior solution for $a$, implies that $(\phi \tau L)-k p c$ must be greater than 0 . This implies a threshold for $k$ as follows: $\tilde{k}=(\phi \tau L) / c$. Hence, $a>0$ for $k \in[0, \tilde{k})$ and $a=0$ for $k \in[\tilde{k}, \bar{k}]$.

\section{A.2. (Dual) Ramsey Problem - Section 3.1}

Consider a buyer's indirect utility function $v(p, \phi, \tau)=u[c(1 / p, \phi, \tau), L(1 / p, \phi, \tau), S(a(1 / p, \phi, \tau))]$ and its corresponding Roy's identity $\partial v / \partial p=-\mu L / p$, where $\mu$ is the buyer's marginal utility of income. Using the first-order conditions of the consumer's problem, the effects of tax and enforcement policies on the buyer's indirect utility are as follows: $(\partial v / \partial \tau)=(\partial v / \partial p)(\partial p / \partial \tau)-\mu p \phi a L,(\partial v / \partial \phi)=$ $(\partial p / \partial \phi)(\partial p / \partial \phi)-\mu p \tau a L$ and $(\partial v / \partial \theta)=(\partial v / \partial p)(\partial p / \partial \theta)$. The first-order conditions for the Ramsey problem (9) with respect to $\{\tau, \theta, \phi\}$ are, respectively:

$$
\left.\begin{array}{c}
\left(\frac{\mu}{p}\right) L \frac{\partial p}{\partial \tau}-\mu p \phi a L=\lambda\left\{\begin{array}{c}
L \\
{\left[\begin{array}{c}
a(1-\phi)+\left(\frac{\partial a}{\partial p} \frac{\partial p}{\partial \tau}+\frac{\partial a}{\partial \tau}\right)(\tau(1-\phi)-\gamma \tau+(1-\gamma) \theta \rho) \\
\left.+(1-a)\left(\gamma+\frac{\partial \gamma}{\partial \tau}+\frac{\partial \gamma}{\partial a}\left(\frac{\partial a}{\partial p} \frac{\partial p}{\partial \tau}+\frac{\partial a}{\partial \tau}\right)+\frac{\partial \gamma}{\partial p} \frac{\partial p}{\partial \tau}\right)(\tau-\theta \rho)\right)
\end{array}\right]} \\
+\left(\frac{\partial L}{\partial p} \frac{\partial p}{\partial \tau}+\frac{\partial L}{\partial \tau}\right)[a \tau(1-\phi)+(1-a)(\gamma \tau+(1-\gamma) \theta \rho)]
\end{array}\right\} \\
\left(\frac{\mu}{p}\right) L \frac{\partial p}{\partial \theta}=\lambda\left\{\begin{array}{l}
L\left[\begin{array}{l}
\left(\frac{\partial a}{\partial p} \frac{\partial p}{\partial \theta}\right)(\tau(1-\phi)-(\gamma \tau+(1-\gamma) \theta \rho)) \\
+(1-a)\left[\left(\frac{\partial \gamma}{\partial \theta}+\frac{\partial \gamma}{\partial a} \frac{\partial a}{\partial p} \frac{\partial p}{\partial \theta}+\frac{\partial \gamma}{\partial p} \frac{\partial p}{\partial \theta}\right)(\tau-\theta \rho)+\rho(1-\gamma)\right]
\end{array}\right] \\
+\left(\frac{\partial L}{\partial p} \frac{\partial p}{\partial \theta}\right)[a \tau(1-\phi)+(1-a)(\gamma \tau+(1-\gamma) \theta \rho)]-N
\end{array}\right\} \\
\left(\begin{array}{l}
\mu \\
p
\end{array}\right) L \frac{\partial p}{\partial \phi}-\mu p \tau a L=\lambda\left\{\begin{array}{l}
L\left[\begin{array}{l}
\left(\frac{\partial a}{\partial p} \frac{\partial p}{\partial \phi}+\frac{\partial a}{\partial \phi}\right)(\tau(1-\phi)-(\gamma \tau+(1-\gamma) \theta \rho)) \\
+(1-a)\left(\left[\frac{\partial \gamma}{\partial a}\left(\frac{\partial a}{\partial p} \frac{\partial p}{\partial \phi}+\frac{\partial a}{\partial \phi}+\frac{\partial \gamma}{\partial p} \frac{\partial p}{\partial \phi}\right)\right](\tau-\theta \rho)-a \tau\right)
\end{array}\right] \\
+\left(\frac{\partial L}{\partial p} \frac{\partial p}{\partial \phi}+\frac{\partial L}{\partial \phi}\right)[a \tau(1-\phi)+(1-a)(\gamma \tau+(1-\gamma) \theta \rho)]
\end{array}\right.
\end{array}\right\}
$$


After manipulating problem (9)'s first-order conditions with respect to $\tau, \theta$ and $\phi$, we obtain conditions that the optimal policy choices must satisfy, namely that the net effect of policies on an consumer's welfare is equal to their net effect on (expected) tax collection in utility terms follows:

$$
\begin{aligned}
\left(\frac{\mu}{p}\right) L \frac{\partial p}{\partial \theta} & =\lambda\left[L\left(\frac{\partial T^{e}}{\partial p} \frac{\partial p}{\partial \theta}+\frac{\partial T^{e}}{\partial \theta}\right)+T^{e}\left(\frac{\partial L}{\partial p} \frac{\partial p}{\partial \theta}-N\right)\right], \\
\left(\frac{\mu}{p}\right) L \frac{\partial p}{\partial \phi}-\mu p \tau a L & =\lambda\left\{L\left(\frac{\partial T^{e}}{\partial p} \frac{\partial p}{\partial \phi}+\frac{\partial T^{e}}{\partial \phi}\right)+T^{e}\left[\left(\frac{\partial L}{\partial p} \frac{\partial p}{\partial \phi}\right)+\frac{\partial L}{\partial \phi}\right]\right\}, \\
\left(\frac{\mu}{p}\right) L \frac{\partial p}{\partial \tau}-\mu p \phi a L & =\lambda\left\{L\left(\frac{\partial T^{e}}{\partial p} \frac{\partial p}{\partial \tau}+\frac{\partial T^{e}}{\partial \tau}\right)+T^{e}\left[\frac{\partial L}{\partial \tau}+\left(\frac{\partial L}{\partial p} \frac{\partial p}{\partial \tau}\right)\right]\right\},
\end{aligned}
$$

where

$$
\begin{aligned}
\frac{\partial T^{e}}{\partial \theta}= & {\left[(1-a)\left(\frac{\partial \gamma}{\partial \theta}(\tau-\theta \gamma)+\rho(1-\gamma)\right)\right], } \\
\frac{\partial T^{e}}{\partial p}= & \frac{\partial a}{\partial p}[\tau(1-\phi)-(\gamma \tau+(1-\gamma) \theta \rho)]+(1-a)\left[\left(\frac{\partial \gamma}{\partial a} \frac{\partial a}{\partial p}+\frac{\partial \gamma}{\partial p}\right)(\tau-\theta \rho)\right] \\
\frac{\partial T^{e}}{\partial \phi}= & \frac{\partial a}{\partial \phi}[\tau(1-\phi)-(\gamma \tau+(1-\gamma) \theta \rho)]-a \tau, \\
\frac{\partial T^{e}}{\partial \tau}= & a(1-\phi)+\frac{\partial a}{\partial \tau}[\tau(1-\phi)-(\gamma \tau+(1-\gamma) \theta \rho)+(1-a)(\tau-\theta \rho)] \\
& +(1-a) \gamma+\frac{\partial \gamma}{\partial \tau}[(1-a)(\tau-\theta \rho)]
\end{aligned}
$$

To the extent that tax and enforcement policies affect the good's price, the planner's policy trade-off can also be expressed in terms of price-elasticity. After some manipulation, expressions (10) and (11) can be rewritten as:

$$
\begin{aligned}
& \frac{\epsilon^{(p, \phi)}}{\epsilon^{(p, \tau)}}=\frac{\left[\epsilon^{(L, \phi)}+\epsilon^{\left(T^{e}, \phi\right)}\right]+\left(\frac{\mu}{\lambda}\right)\left(\frac{p \phi a \tau}{T^{e}}\right)}{\left[\epsilon^{(L, \tau)}+\epsilon^{\left(T^{e}, \tau\right)}\right]+\left(\frac{\mu}{\lambda}\right)\left(\frac{p \phi a \tau}{T^{e}}\right)} \\
& \frac{\epsilon^{(p, \phi)}}{\epsilon^{(p, \theta)}}=\frac{\left.\left[\epsilon^{(L, \phi}\right)+\epsilon^{\left(T^{e}, \phi\right)}\right]+\left(\frac{\mu}{\lambda}\right)\left(\frac{p \phi a \tau}{T^{e}}\right)}{\left[\epsilon^{\left(T^{e}, \theta\right)}\right]-\frac{N \theta}{\lambda T^{e}}}
\end{aligned}
$$

where $\epsilon^{(m, \Upsilon)}=(\Upsilon / m)(\partial m / \partial \Upsilon)$ is the elasticity of a variable $m=p, T^{e}, L$ with respect to a policy instrument $\Upsilon=\tau, \theta, \phi$. Equation (33) states that the government should increase tax collection through policy $\phi$ vis-a-vis policy $\tau$ up to the point where the ratio of price elasticities of these two policies (LHS of equation 33) is equal to the ratio of the elasticity of tax collection with respect to the policy $\phi\left(\epsilon^{(L, \phi)}+\epsilon^{\left(T^{e}, \phi\right)}\right)$ to the counterpart elasticity of tax collection with respect to the policy $\tau\left(\epsilon^{(L, \tau)}+\epsilon^{\left(T^{e}, \tau\right)}\right)$. The additional term $(p \phi a \tau) / T^{e}$ captures the ratio between a buyer's auditing income and the total expected tax revenue. The interpretation of equation (34) follows similar arguments, the only differences being that the detection probability $\theta$ does not affect labor allocation directly, i.e., $\epsilon^{(L, \theta)}=0$, and the use of this policy entails a resource cost of $N \theta$.

\section{A.3. (Primal) Ramsey Problem - Section 3.2}

Definition 1 A competitive equilibrium is a policy $\Upsilon=\{\tau, \theta, \rho, \phi\}$, government spending $\bar{G}=$ $\{G, N\}$, private agents' allocations $x=\{c, a, L, \gamma\}$, a price system $\bar{P}=\{p, w\}$ such that given 
the policy, government spending and the price system, the resulting households' and firms' allocations choices maximize consumers' utilities and firms' profits and satisfies the government's budget constraint, the economy's resource constraint and market-clearing conditions.

Definition 2 A Ramsey equilibrium in this economy is a policy $\Upsilon$, an allocation rule $x$ and a price rule $\bar{P}$ that satisfy the following two conditions: $(i)$ the policy $\Upsilon$ maximizes $(3)$ subject to the government budget constraint (6) with allocations and prices given by $x$ and $\bar{P}$ and (ii) for every $\Upsilon^{\prime}$, the allocation $x\left(\Upsilon^{\prime}\right)$, the price rule $\bar{P}\left(\Upsilon^{\prime}\right)$ and the policy $\Upsilon^{\prime}$ constitute a competitive equilibrium.

Proposition 5 The household's allocations and policy $\Upsilon_{0}$, in a competitive equilibrium, satisfy the economy's resource constraint (37) and the implementability constraint (35). Furthermore, given households' choices and $\Upsilon_{0}$, prices and policies can be constructed such that they constitute a competitive equilibrium.

The proof of this Proposition follows directly from Chari, Christiano and Kehoe (1991) and is omitted.

The implementability constraint is obtained from the buyers' budget constraint by expressing prices and policy instruments in terms of allocations through their marginal efficiency conditions. That is,

$$
u_{1} c-u_{2} L=0 .
$$

The social planner is also constrained to choose allocations that are feasible in this economy. This implies that the resource constraint must be imposed on the planner's problem. Following the primal approach to the Ramsey problem, we must express this constraint in terms of allocations only. But notice that the audit probability $\theta$ appears in the equation (7). Hence we need to express $\theta$ in terms of allocations, which is an interesting aspect of our problem.

In the derivation of the implementability constraint, equation (35), we only used the buyer's first-order conditions with respect to consumption and labor. But the planner has also to take into account the buyer's first-order condition with respect to the fraction of purchases with receipt $(a)$ and the seller's optimal choices of $\gamma$ and $L$. Imposing these conditions on the Ramsey planner's problem means that the real wage paid by the firm and the real wage received by the worker, equations (2) and (5), respectively, coincide in equilibrium. This strategy is similar to the one employed by Jones, Manuelli and Rossi (1997). Hence, solving for $\theta$ we obtain:

$$
\theta=\frac{1}{\rho}\left[1-H(\xi)+(1-\gamma)(a+(1-a) \gamma) H_{\gamma}(\xi)-\frac{u_{2}}{u_{1}}\left(1-\frac{a S_{a}}{L}\right)\right]=\Phi(c, L, a, \gamma ; \rho)
$$

We then substitute $\theta=\Phi(c, L, a, \gamma ; \rho)$ into equation (7) and rewrite the economy's resource constraint as follows:

$$
c+G+\Phi(c, L, a, \gamma ; \rho) N+\xi H(\xi) L=L
$$

\section{Proposition 3}

Proof. The first order conditions of problem (13) are as follows:

$$
\begin{aligned}
Z_{c}^{*} & =\left[1+\Phi_{c}^{*} N\right] \lambda_{2}^{*} \\
Z_{L}^{*} & =\left[\Phi_{L}^{*} N+\xi^{*} H\left(\xi^{*}\right)-1\right] \lambda_{2}^{*} \\
Z_{a}^{*} & =\left[\Phi_{a}^{*} N+-\left(\left(1-\gamma^{*}\right) H\left(\xi^{*}\right)-\xi^{*} H_{a^{*}}\right) L^{*}\right] \lambda_{2}^{*} \\
\Phi_{\gamma}^{*} N & =\left[\left(1-a^{*}\right) H\left(\xi^{*}\right)-\xi^{*} H_{\gamma^{*}}\right] L^{*}
\end{aligned}
$$


where $\lambda_{2}$ is the Lagrange multiplier on the resource constraint, equation (37), and $Z_{c}^{*}, Z_{L}^{*}, Z_{a}^{*}, \Phi_{c}^{*}$, $\Phi_{L}^{*}, \Phi_{a}^{*}, \Phi_{\gamma}^{*}$ are defined as follows:

$$
\begin{aligned}
Z_{c}^{*} & =u_{1}^{*}+\lambda_{1}^{*}\left[u_{11}^{*} c^{*}+u_{1}^{*}\right] \\
Z_{L}^{*} & =-u_{2}^{*}-\lambda_{1}^{*}\left[u_{22}^{*} L^{*}+u_{2}^{*}\right] \\
Z_{a}^{*} & =-u_{2}^{*} S_{a^{*}} \\
\Phi_{c}^{*} & =\frac{1}{\rho}\left(\frac{u_{11}^{*}}{\left(u_{1}^{*}\right)^{2}} \frac{u_{2}^{*}}{L^{*}}\right)\left(L^{*}-a^{*} S_{a}^{*}\right) \\
\Phi_{L}^{*} & =-\frac{1}{\rho}\left(\frac{1}{u_{1}^{*} L^{*}}\right)\left[u_{22}^{*}\left(L^{*}-a^{*} S_{a}^{*}\right)+u_{2}^{*} \frac{a^{*} S_{a}^{*}}{L^{*}}\right] \\
\Phi_{a}^{*} & =\frac{1}{\rho}\left\{-H_{a}^{*}+\left(1-\gamma^{*}\right)\left[\left(1-\gamma^{*}\right) H_{\gamma}^{*}+\left(a^{*}+\left(1-a^{*}\right) \gamma^{*}\right) H_{\gamma a}^{*}\right]-\left(\frac{u_{2}^{*}}{u_{1}^{*} L^{*}}\right)\left(S_{a}^{*}+a^{*} S_{a a}^{*}\right)\right\} \\
\Phi_{\gamma}^{*} & =\frac{1}{\rho}\left\{-H_{\gamma}^{*}-\left(a^{*}+\left(1-a^{*}\right) \gamma^{*}\right) H_{\gamma}^{*}+\left(1-\gamma^{*}\right)\left[\left(1-a^{*}\right) H_{\gamma}^{*}+\left(a^{*}+\left(1-a^{*}\right) \gamma^{*}\right) H_{\gamma \gamma}^{*}\right]\right\}
\end{aligned}
$$

Combining the Ramsey's and seller's first-order conditions with respect to $\gamma$ we obtain

$$
\tau^{*}=\theta^{*} \rho+\frac{\Phi_{\gamma}^{*} N}{\left(1-a^{*}\right) L^{*}}
$$

Combine equations (38) and (39) and equations (42) and the seller's first-order condition with respect to labor to obtain

$$
\frac{w^{*}}{p^{*}}=\Phi_{L}^{*} N-\left[1+\Phi_{c}^{*} N\right] \frac{Z_{L}^{*}}{Z_{c}^{*}}-\left(\frac{a^{*}+\left(1-a^{*}\right) \gamma^{*}}{\left(1-a^{*}\right) L^{*}}\right) \Phi_{\gamma}^{*} N-\theta^{*} \rho .
$$

The optimal (government) auditing probability $\theta^{*}$, equation (15), is implicitly determined by (43) and (5). Plugging (15) into (42) we obtain (14). Finally, combine equations (38) and (40) and the buyer's first-order condition with respect to $a$ and (42) to obtain (16). Normalizing the nominal wage $w=1$, the good's optimal price, is determined by equation (2).

\section{References}

[1] Akerlof, G. A. 1980. "A theory of social custom, of which unemployment may be one consequence", Quarterly Journal of Economics, 94, 749-75.

[2] Allingham, M. and Sandmo, A. 1972. "Income tax evasion: A theoretical analysis", Journal of Public Economics $1323-338$.

[3] Atkinson, A.B. and Stiglitz, J.E., 1980. Lectures on Public Economics. McGraw-Hill, New York.

[4] Blundell, Richard, MaCurdy, Thomas E., 1999. Labor supply: a review of alternative approaches. In: Aschenfleter, O., Card, D. (Eds.), Handbook of Labor Economics, vol. 3A. Elsevier, Amsterdam. 
[5] Boadway, Robin and Gahvari, Firouz, 2006. "Optimal taxation with consumption time as a leisure or labor substitute," Journal of Public Economics, Elsevier, vol. 90(10-11), pages 18511878.

[6] Boadway, Robin; Nicolas Marceau and Steeve Mongrain, 2002. "Joint tax evasion," Canadian Journal of Economics, Canadian Economics Association, vol. 35(3), pages 417-435.

[7] Boadway, Robin; Nicolas Marceau and Steeve Mongrain, 2007. "Redistributive Taxation under Ethical Behaviour", Scandinavian Journal of Economics, Wiley Blackwell, vol. 109(3), pages 505-529, 09.

[8] Chang, Juin-jen and Ching-chong Lai, 2004. "Collaborative tax evasion and social norms: why deterrence does not work," Oxford Economic Papers, Oxford University Press, vol. 56(2), pages 344-368.

[9] Chari V.V., Christiano L., Kehoe P., 1991. Optimal fiscal and monetary policy: Some recent results. Journal of Money, Credit and Banking 23, 519-539.

[10] Chari, V.V., Lawrence J. Christiano, and Patrick J. Kehoe, 1994, "Optimal Fiscal Policy in a Business Cycle Model," Journal of Political Economy, Vol. 102, pp. 617-52.

[11] Cremer, Helmuth and Gahvari, Firouz, 1993. "Tax evasion and optimal commodity taxation," Journal of Public Economics, Elsevier, vol. 50(2), pages 261-275.

[12] Cremer, Helmuth and Gahvari, Firouz, 1994."Tax Evasion, Concealment and the Optimal Linear Income. Scandinavian Journal of Economics, vol. 96(2), pages 219-39.

[13] Das-Gupta, Arindam and Gang, Ira N, 1996. "A Comparison of Sales Taxes," Public Finance. Finances publiques, , vol. 51(2), pages 217-25.

[14] Elster, Jon. (1989). Social norms and economic theory. Journal of Economic Perspectives, 3, no. $4,99-117$

[15] Gahvari,, Firouz, 2007."On Optimal Commodity Taxes When Consumption Is Time Consuming," Journal of Public Economic Theory, vol. 9(1), pages 1-27, 02.

[16] Gahvari, F., and C. C. Yang, 1993. "Optimal commodity taxation and household consumption activities", Public Finance Quarterly 21, 479-487.

[17] Gordon, R. and Li, W. 2009. "Tax structures in developing countries: Many puzzles and a possible explanation," Journal of Public Economics, vol. 93(7-8), pages 855-866.

[18] Huang, Che-Chiang, K.L. Glen Ueng, 2012, On the Non-equivalence of Specific and Ad Valorem Taxation in Competitive Markets, Mimeo. 12th Public economic Theory meeting, Taipei.

[19] Jones, Larry E.; Rodolfo E. Manuelli; and Peter E. Rossi (1997). "On the optimal taxation of capital income," Journal of Economic Theory 73(1), 93-117.

[20] Kagan, A. and Scholz, T., 'The criminology of the corporation and regulatory enforcement strategies', in Hawkins, K. and Thomas, J.M. (eds.), Enforcing regulation, Boston, Kluwer Nijhoff, 1984. 
[21] Kaplow, L. 1990. "Optimal taxation with costly enforcement and evasion". Journal of Public Economics 43, pp. 221-236.

[22] Kleven, H. J., 2004. "Optimum taxation and the allocation of time", Journal of Public Economics $88,545-557$.

[23] Lucas R., Stokey N., 1983. Optimal fiscal and monetary policy in an economy without capital. Journal of Monetary Economics 12, 55-93.

[24] Marchese, C. 2009. "Rewarding the Consumer for Curbing the Evasion of Commodity Taxes?," FinanzArchiv: Public Finance Analysis, vol. 65(4), pages 383-402.

[25] Murphy, K., 'Enforcing tax compliance: To punish or persuade?', Economic Analysis and Policy, 38(1), 2008, pp. 113-35.

[26] Paschoal, B., 2012. Punição, recompensa, persuasão e ajuda : estratégias regulatórias a partir do caso Nota Fiscal Paulista. http://hdl.handle.net/10438/10380.

[27] Renooy, P., Ivarsson, S., Wusten-Gritsai, O. van der and Meijer, R., Undeclared work in an enlarged Union: An analysis of shadow work - An in-depth study of specific items, Brussels, European Commission, 2004.

[28] Sandmo, A., 1974. A note on the structure of optimal taxation. American Economic Review 64, 701-706.

[29] SBC (Small Business Council), Small business in the informal economy: Making the transition to the formal economy, London, SBC, 2004.

[30] Slemrod, J., 'Why people pay taxes: Introduction', in Slemrod, J. (ed.), Why people pay taxes, Ann Arbor, University of Michigan Press, 1992.

[31] Slemrod, Joel. 2008. "Does it matter who writes the check to the government? The economics of tax remittance." National Tax Journal, 61(2): 251-275.

[32] Tanzi, Vito and Parthasarathi Shome. 1993. "A primer on tax evasion", (pp. 807-828) in IMF Staff Papers, VoL. 40, No. 4. Washington D.C.

[33] Usher, D. 1986. "Tax evasion and the marginal cost of public funds". Economic Inquiry 24 (1986), pp. 563-586.

[34] Williams, C.C., The hidden enterprise culture: Entrepreneurship in the underground economy, Cheltenham, Edward Elgar, 2006.

[35] Williams, C.C. and Renooy, P. 2008. "Tackling Undeclared Work in the European Union"', European Foundation for the Improvement of Living and Working Conditions, Dublin.

[36] Yitzhaki, S. 1974. "Income tax evasion: A theoretical analysis," Journal of Public Economics, vol. 3(2), pages 201-202.

[37] Young, H. P. and Burke, M. 2001. Competition and Custom in Economic Contracts: A Case study of Illinois Agriculture, American Economic Association, vol. 91(3), pages 559-573. 